\title{
Stent-assisted coil placement for unruptured cerebral aneurysms
}

\author{
Pascal Jabbour, M.D., Christopher Koebbe, M.D., Erol Veznedaroglu, M.D., \\ Ronald P. Benitez, M.D., AND Robert Rosenwasser, M.D.
}

Department of Neurosurgery, Thomas Jefferson University School of Medicine, Jefferson Hospital for Neuroscience, Philadelphia, Pennsylvania

\begin{abstract}
Object. The treatment of wide-necked cerebral aneurysms represents a challenging problem for neurosurgeons. The recent development of stents has provided clinicians with the ability to treat these aneurysms while keeping the parent vessel patent. The long-term occlusion rate of aneurysms treated with stent-assisted coil placement has yet to be investigated. The authors report the use of a new intracranial stent - the Neuroform microstent-in the treatment of unruptured wide-necked cerebral aneurysms.

Methods. Thirty-two patients harboring unruptured wide-necked intracranial aneurysms underwent a stent-assisted coil placement procedure. Patients were pretreated with antiplatelet agents, and a stent was positioned across the neck of the aneurysm. The next step was the insertion of coils into the aneurysm cavity. Patients received anticoagulation therapy for 24 hours after the procedure.

All 32 patients with unruptured wide-necked cerebral aneurysms were suitable candidates for this procedure. Occlusion of at least $90 \%$ of the aneurysm was achieved in 24 patients (75\%) and $0 \%$ occlusion was observed in five patients (15\%). Two patients experienced thromboembolic events, one of which was directly related to the stent. The overall complication rate was $6.3 \%$.

Conclusions. Intracranial stents will be used more frequently in the new era of endovascular management of widenecked cerebral aneurysms. With some technical improvements and more data on long-term occlusion rates, this new modality should improve the occlusion of wide-necked cerebral aneurysms while protecting the parent vessel.
\end{abstract}

KEY WORDS - unruptured aneurysm - intracranial stent • coil occlusion

Endovascular techniques for treatment of cerebral aneurysms offer a less invasive alternative than surgical clipping. ${ }^{17-20}$ Recent publications have described lower complication rates with coil embolization of aneurysms in certain locations and in patients with high-grade lesions. 3,5,9,10,21,22,33 Guglielmi detachable coils, which were introduced in the early 1990s, are considered the preferred endovascular treatment for intracranial aneurysms. ${ }^{2,11,27,30,34}$ This technique still has many limitations, however, especially in wide-necked, dissecting, or fusiform lesions. ${ }^{6,7,12}$ New technical improvements, such as three-dimensional coils, balloon-assisted remodeling, and microstents have allowed endovascular surgeons to treat previously difficult lesions. ${ }^{23,26,28,29,31,36}$ These new techniques are believed to improve occlusion rates and provide better long-term protection from subarachnoid hemorrhage. ${ }^{1}$ The first case of intracranial stent-assisted coil placement in a posterior circulation aneurysm was reported in 1997 by Higashida, et al., ${ }^{13}$ followed by a case of an anterior circulation aneurysm reported in 1998 by Mericle, et al..$^{27}$ In this article we present our experience with stent-assisted coil placement in unruptured aneurysms.

Abbreviations used in this paper: $\mathrm{BA}=$ basilar artery; $\mathrm{PCo} \mathrm{A}=$ posterior communicating artery.

\section{CLINICAL MATERIAL AND METHODS}

\section{Patient Selection}

A total of 32 patients with unruptured aneurysms were treated with the stent-assisted coil placement technique. These patients ranged in age from 34 to 71 years. The distribution of aneurysm location was as follows: paraclinoid (15 lesions), BA (eight), PCoA (three), posterior inferior cerebellar artery (one), internal carotid artery bifurcation (two), vertebral artery (one), and cavernous carotid artery (two). Of these, 27 aneurysms were initially treated with stent placement, followed by coil insertion, whereas five aneurysms received stents only. Patients harboring a widenecked aneurysm were selected for stent-assisted coil delivery (a wide-necked aneurysm is defined as one with a neck width $>4 \mathrm{~mm}$ and/or a fundus/neck ratio $\leq 2$ ). Pretreatment with $325 \mathrm{mg}$ aspirin and $75 \mathrm{mg}$ clopidogrel was administered orally to all patients for at least 3 days prior to the procedure.

\section{Stent Placement}

General anesthesia administered endotracheally and neurophysiological monitoring were used for all procedures. After access to the femoral artery was obtained, a bolus of $5000 \mathrm{U}$ heparin was administered with the goal of 
increasing the activated clotting time to twice the baseline. All stents were placed through a No. 6 French guide catheter (Envoy; Cordis Endovascular, Miami Lakes, FL) after cerebral angiography was performed with the aid of a calibrated fiducial marker to render vessel and aneurysm measurements. Stents are sized based on the largest diameter of the parent vessel in which the device is to be placed. A stent should be slightly oversized rather than undersized. The stent exerts an outward radial force, which allows it to lie against the vessel walls. Despite this radial force, we have seen no significant change in the diameter of the vessel containing the device. The stent will open to match the diameter of the vessel and will change from smaller to larger diameters with no apparent change in vessel caliber.

The Neuroform stent (Boston Scientific, Natick, MA) is intended to be positioned over a microguidewire with the use of a No. 2 French stabilizer. To perform this technique, a microguidewire (Transcend $300 \mathrm{~cm}$; Boston Scientific) is navigated through a microcatheter beyond the aneurysm and into a distal vessel. The microcatheter is then exchanged for the stent No. 3 French microcatheter and No. 2 French stabilizer catheter. With the stent in position, the stabilizer catheter is used to hold the device in place while it is unsheathed in the microcatheter. The microguidewire can then be used to access the aneurysm. In our early experience, we have found this system difficult to use. There is a large amount of friction within the system, which results in tremendous difficulty in advancing the coaxial system. Because of this difficulty, we have modified the documented stent placement procedure.

In our modification, the No. 3 French stent microcatheter can be navigated with the use of a $200-\mathrm{cm}$ microguidewire to the aneurysm or exchanged with a microguidewire. Once the stent is positioned at the aneurysm site, the microguidewire is removed. At this point, a microguidewire cannot be reintroduced through the stent while the microcatheter remains in the body. With the aid of a digital road map, a coil pusher (Boston Scientific/Cordis Endovascular) is navigated through the No. 3 French microcatheter up to the distal stent marker. Then, with the simultaneous use of biplane fluoroscopy and a digital road map, the stent is advanced through the microcatheter until the proximal stent marker reaches the distal marker of the No. 3 French microcatheter. With the stent positioned so that the distal portion is placed in a desirable location, the coil pusher is used to push the stent out of the No. 3 French microcatheter. Once the distal end of the stent is positioned and lies against the vessel wall, the coil pusher can act like the No. 2 French stabilizer to hold the proximal portion of the device in place while the stent is unsheathed from the No. 3 French microcatheter. Ideally, the stent should be positioned so that its proximal end is located on the most horizontal segment of the artery. Placing the stent on or near a curve increases the difficulty of navigating a microcatheter into the device and subsequently into the aneurysm. With this technique, the No. 2 French stabilizer catheter is not used. The use of a coil pusher effectively eliminates any problems with catheter friction. Recently, however, stent placement was not possible in several cases.

\section{Endovascular Occlusion}

Once the microcatheter is connected to allow continu- ous fluid flush, it can be navigated over a microguidewire to the proximal end of the stent. With simultaneous biplane road mapping, the microcatheter and microguidewire can then be navigated into the proximal end of the stent. Once the microguidewire is positioned in the stent, the microcatheter can be advanced into the device. The aneurysm can then be catheterized with the microguidewire and the catheter. Coil placement in the aneurysm can then be performed in the standard way.

\section{Postoperative Management}

All patients were transferred to the neurosurgical intensive care unit after the procedure, and they all received intravenously administered heparin for 24 hours with a target partial thromboplastin time of 60 to 70 seconds. Once heparin was stopped, dextran 40 was administered for the next 24 hours. The femoral sheath was removed 24 hours after the procedure was completed. Clopidogrel was discontinued at 6 weeks and aspirin therapy was maintained indefinitely.

\section{RESULTS}

We achieved $100 \%$ occlusion in 18 cases, $99 \%$ in three, greater than $90 \%$ in three, less than $90 \%$ in three, and there was technical failure in five cases. In the majority of the patients (21) an acute occlusion rate of 99 to $100 \%$ was observed (Table 1).

Two patients experienced thromboembolic events; one of them had undergone stent-assisted coil occlusion of a basilar apex aneurysm through a dominant vertebral artery. Postoperatively the patient was hemiparetic and magnetic resonance imaging demonstrated changes at the middle cerebellar peduncle and brainstem. This event was thought to be secondary to a basilar perforating vessel occlusion during placement of the guide catheter. At the 6week follow-up visit she had only mild residual hemiparesis. Another patient with a large PCoA aneurysm and fetal posterior cerebral circulation experienced a delayed transient ischemic attack after prematurely discontinuing clopidogrel at home. The patient was readmitted 10 days after initial discharge with new onset of right-sided numbness and a right visual field cut. Her deficits resolved 48 hours after starting therapy with heparin and clopidogrel. The patient was discharged with instructions to maintain Coumadin therapy for 3 months, and clopidogrel and aspirin therapy were continued. There were no instances of acute parent-vessel injury or delayed stenosis secondary to stent placement. Further angiographic follow-up review is obviously needed.

\section{ILLUSTRATIVE CASE}

Click here to view the video clip using RealOne Player or Windows Media Player: The clip shows the procedure for stentassisted coil placement in a paraclinoid aneurysm.

\section{DISCUSSION}

The use of stents in intracranial vascular lesions has prompted the development of complex management strategies for treating aneurysms. ${ }^{8,15,24,25}$ The early success of stent placement for abdominal aortic aneurysms and other 
TABLE 1

Demographic data in 32 patients who underwent stent-assisted occlusion of aneurysms*

\begin{tabular}{|c|c|c|c|c|}
\hline Case No. & Age (yrs) & $\begin{array}{l}\text { Aneurysm } \\
\text { Location }\end{array}$ & Procedure & $\begin{array}{c}\text { Occlusion } \\
(\%)\end{array}$ \\
\hline 1 & 57 & $\mathrm{BA}$ & coil/stent & 100 \\
\hline 2 & 49 & lt COphA & coil/stent & 99 \\
\hline 3 & 61 & rt COphA & stent only & 0 \\
\hline 4 & 42 & rt COphA & stent only & 0 \\
\hline 5 & 61 & lt COphA & stent only & 0 \\
\hline 6 & 55 & rt PICA & coil/stent & 99 \\
\hline 7 & 55 & rt paraclinoid & coil/stent & 100 \\
\hline 8 & 49 & rt COphA & coil/stent & $<90$ \\
\hline 9 & 45 & rt COphA & coil/stent & $>90$ \\
\hline 10 & 34 & rt COphA & coil/stent & 100 \\
\hline 11 & 42 & $\mathrm{BA}$ & coil/stent & 100 \\
\hline 12 & 44 & 1t ICA bif & coil/stent & 99 \\
\hline 13 & 62 & BA & coil/stent & $>90$ \\
\hline 14 & 54 & lt SCA & coil/stent & 100 \\
\hline 15 & 66 & rt paraclinoid & coil/stent & $<90$ \\
\hline 16 & 53 & rt paraclinoid & coil/stent & 100 \\
\hline 17 & 71 & rt PCoA & coil/stent & 100 \\
\hline 18 & 39 & midbasilar & coil/stent & $>90$ \\
\hline 19 & 48 & BA & coil/stent & 100 \\
\hline 20 & 59 & lt $\mathrm{PCoA}$ & coil/stent & 100 \\
\hline 21 & 70 & lt $\mathrm{PCoA}$ & coil/stent & $<90$ \\
\hline 22 & 45 & $\mathrm{BA}$ & coil/stent & 100 \\
\hline 23 & 59 & It paraclinoid & coil/stent & 100 \\
\hline 24 & 56 & rt ICA bif & coil/stent & 100 \\
\hline 25 & 61 & $\mathrm{BA}$ & stent only & 0 \\
\hline 26 & 42 & rt paraclinoid & coil/stent & 100 \\
\hline 27 & 49 & rt paraclinoid & coil/stent & 100 \\
\hline 28 & 61 & rt paraclinoid & stent only & 0 \\
\hline 29 & 42 & rt CCF & coil/stent & 100 \\
\hline 30 & 39 & rt paraclinoid & coil/stent & 100 \\
\hline 31 & 45 & rt paraclinoid & coil/stent & 100 \\
\hline 32 & 64 & lt cavernous & coil/stent & 100 \\
\hline
\end{tabular}

* Bif = bifurcation; $\mathrm{CCF}=$ carotid cavernous fistula; $\mathrm{COphA}=$ carotid ophthalmic artery; PICA = posterior inferior cerebellar artery; SCA = superior cerebellar artery.

peripheral lesions like traumatic extracranial carotid artery dissections and pseudoaneurysms has been a valuable contribution to the development of intracranial stent delivery techniques., $, 14,16,27,32,35,37$ There are still some difficulties and complications ranging from technical pitfalls to thromboembolic events that are encountered with the use of intracranial stents. ${ }^{1}$

\section{Stent Placement}

The most significant difficulty encountered to date has been with stent placement into the parent vessel. We have modified the initial delivery system as previously described in Clinical Material and Methods. Despite this modification, we have encountered some difficulties with stent delivery in six cases. In all of them we were unable to initiate movement of the stent in the No. 3 French microcatheter. It may be advisable to break the stent on the table before placing the catheter in the body. This can be achieved by advancing the stabilizer into the No. 3 French catheter and moving the stent to break the initial friction.

Care must be taken to avoid stretching and rupture of the lesion by the catheter when delivering the stent and moving it within the microcatheter. The stent should ade- quately bridge the neck of the aneurysm. In several cases we noted parent-vessel vasospasm that resolved without treatment, and after we changed the method of stent delivery we have not encountered this problem.

\section{Aneurysm Catheterization}

The problem encountered during this phase was stent movement or difficulty in gaining access to the proximal end of the device, which led us to abort the aneurysm catheterization in four cases. One modification of the technique involves placing the catheter tip within the aneurysm, followed by stent placement. This ensures the ability to place coils within the aneurysm but may increase the risk associated with the procedure if the catheter is prevented from backing out of the lesion.

\section{Coil Placement}

The presence of the stent did not affect our ability to deliver the coils. The size of the opening between stent interstices is the same as the No. 2 French catheter. When the stent is placed in a tortuous vessel segment, these cells may be stretched to a larger diameter, thus increasing the risk of coil prolapse. The use of a balloon can be beneficial in keeping the last few coils in place when this occurs.

\section{Thromboembolic Complications}

In our series one patient experienced a thromboembolic event related to stent placement. Premedication with antiplatelet agents is necessary before any stent-assisted procedures are performed. Patients should receive loading doses of aspirin and clopidogrel for at least 3 days. The use of a heparin drip during and for 24 hours after the procedure is crucial to prevent thromboembolic complications. Patients receive a 6-week course of clopidogrel on discharge, and aspirin therapy is continued indefinitely.

\section{CONCLUSIONS}

The impact of stents on the long-term occlusion rate of aneurysms has yet to be investigated. Stent-assisted coil delivery is a useful technical adjunct for treatment of wide-necked aneurysms. Although technical improvements of this device are needed, primarily with regard to the delivery system, further studies are necessary to investigate the long-term results. Longer follow-up review is needed for these patients and should focus on delayed thromboembolic events, delayed parent-vessel stenosis, and long-term occlusion rates. We think that this device represents a significant milestone in the endovascular treatment of challenging intracranial aneurysms.

\section{Disclosure}

Robert H. Rosenwasser, M.D., is a consultant to Boston Scientific Corporation.

\section{References}

1. Benitez RP, Silva MT, Klem J, et al: Endovascular occlusion of wide-necked aneurysms with a new intracranial microstent (Neuroform) and detachable coils. Neurosurgery 54: 1359-1368, 2004

2. Brilstra EH, Rinkel GJ, van der Graaf Y, et al: Treatment of 
intracranial aneurysms by embolization with coils: a systematic review. Stroke 30:470-476, 1999

3. Casasco AE, Aymard A, Gobin YP, et al: Selective endovascular treatment of 71 intracranial aneurysms with platinum coils. J Neurosurg 79:3-10, 1993

4. Duke BJ, Ryu RK, Coldwell DM, et al: Treatment of blunt injury to the carotid artery by using endovascular stents: an early experience. J Neurosurg 87:825-829, 1997

5. Eskridge JM, Song JK: Endovascular embolization of 150 basilar tip aneurysms with Guglielmi detachable coils: results of the Food and Drug Administration multicenter clinical trial. J Neurosurg 89:81-86, 1998

6. Fernandez Zubillaga A, Guglielmi G, Viñuela F, et al: Endovascular occlusion of intracranial aneurysms with electrically detachable coils: correlation of aneurysm neck size and treatment results. AJNR 15:815-820, 1994

7. Gobin YP, Viñuela F, Gurian JH, et al: Treatment of large and giant fusiform intracranial aneurysms with Guglielmi detachable coils. J Neurosurg 84:55-62, 1996

8. Gomez CR, Misra VK, Liu MW, et al: Elective stenting of symptomatic basilar artery stenosis. Stroke 31:95-99, 2000

9. Graves VB, Strother CM, Duff TA, et al: Early treatment of ruptured aneurysms with Guglielmi detachable coils: effect on subsequent bleeding. Neurosurgery 37:640-648, 1995

10. Gruber DP, Zimmerman GA, Tomsick TA, et al: A comparison between endovascular and surgical management of basilar artery apex aneurysms. J Neurosurg 90:868-874, 1999

11. Guglielmi G, Viñuela F, Dion J, et al: Electrothrombosis of saccular aneurysms via endovascular approach. Part 2: Preliminary clinical experience. J Neurosurg 75:8-14, 1991

12. Halbach VV, Higashida RT, Dowd CF, et al: Endovascular treatment of vertebral artery dissections and pseudoaneurysms. J Neurosurg 79:183-191, 1993

13. Higashida RT, Smith W, Gress D, et al: Intravascular stent and endovascular coil placement for a ruptured fusiform aneurysm of the basilar artery. Case report and review of the literature. $\mathbf{J}$ Neurosurg 87:944-949, 1997

14. Horowitz MB, Miller G III, Meyer Y, et al: Use of intravascular stents in the treatment of internal carotid and extracranial vertebral artery pseudoaneurysms. AJNR 17:693-696, 1996

15. Horowitz MB, Purdy PD: The use of stents in the management of neurovascular disease: a review of historical and present status. Neurosurgery 46:1335-1343, 2000

16. Huang A, Baker DM, al-Kutoubi A, et al: Endovascular stenting of internal carotid artery false aneurysm. Eur J Vasc Endovasc Surg 12:375-377, 1996

17. Johnston SC, Higashida RT, Barrow DL, et al: Recommendations for the endovascular treatment of intracranial aneurysms: a statement for healthcare professionals from the Committee on Cerebrovascular Imaging of the American Heart Association Council on Cardiovascular Radiology. Stroke 33:2536-2544, 2002

18. Johnston SC, Wilson CB, Halbach VV, et al: Endovascular and surgical treatment of unruptured cerebral aneurysms: comparison of risks. Ann Neurol 48:11-19, 2000

19. Johnston SC, Zhao S, Dudley RA, et al: Treatment of unruptured cerebral aneurysms in California. Stroke 32:597-605, 2001

20. Koivisto T, Vanninen R, Hurskainen H, et al: Outcomes of early endovascular versus surgical treatment of ruptured cerebral aneurysms. A prospective randomized study. Stroke 31: 2369-2377, 2000

21. Kremer C, Groden C, Hansen HC, et al: Outcome after endovascular treatment of Hunt and Hess grade IV or V aneurysms: comparison of anterior versus posterior circulation. Stroke 30: 2617-2622, 1999

22. Lempert TE, Malek AM, Halbach VV, et al: Endovascular treatment of ruptured posterior circulation cerebral aneurysms. Clinical and angiographic outcomes. Stroke 31:100-110, 2000

23. Levy DI, Ku A: Balloon-assisted coil placement in wide-necked aneurysms. Technical note. J Neurosurg 86:724-727, 1997

24. Levy EI, Boulos AS, Bendok BR, et al: Brainstem infarction after delayed thrombosis of a stented vertebral artery fusiform aneurysm: case report. Neurosurgery 51:1280-1285, 2002

25. Levy EI, Horowitz MB, Koebbe CJ, et al: Transluminal stentassisted angiplasty of the intracranial vertebrobasilar system for medically refractory, posterior circulation ischemia: early results. Neurosurgery 48:1215-1223, 2001

26. Malek AM, Higashida RT, Phatouros CC, et al: Treatment of an intracranial aneurysm using a new three-dimensional-shape Guglielmi detachable coil: technical case report. Neurosurgery 44:1142-1145, 1999

27. Mericle RA, Lanzino G, Wakhloo AK, et al: Stenting and secondary coiling of intracranial internal carotid artery aneurysm: technical case report. Neurosurgery 43:1229-1234, 1998

28. Mericle RA, Wakhloo AK, Rodriguez R, et al: Temporary balloon protection as an adjunct to endosaccular coiling of widenecked cerebral aneurysms: technical note. Neurosurgery 41: 975-978, 1997

29. Phatouros CC, Sasaki TY, Higashida RT, et al: Stent-supported coil embolization: the treatment of fusiform and wide-neck aneurysms and pseudoaneurysms. Neurosurgery 47:107-115, 2000

30. Raftopoulos C, Mathurin P, Boscherini D, et al: Prospective analysis of aneurysm treatment in a series of 103 consecutive patients when endovascular embolization is considered the first option. J Neurosurg 93:175-182, 2000

31. Sekhon LH, Morgan MK, Sorby W, et al: Combined endovascular stent implantation and endosaccular coil placement for the treatment of a wide-necked vertebral artery aneurysm: technical case report. Neurosurgery 43:380-384, 1998

32. Singer RJ, Dake MD, Norbash A, et al: Covered stent placement for neurovascular disease. AJNR 18:507-509, 1997

33. Sturaitis MK, Rinne J, Chaloupka JC, et al: Impact of Guglielmi detachable coils on outcomes of patients with intracranial aneurysms treated by a multidisciplinary team at a single institution. J Neurosurg 93:569-580, 2000

34. Vanninen R, Koivisto T, Saari T, et al: Ruptured intracranial aneurysms: acute endovascular treatment with electrolytically detachable coils - a prospective randomized study. Radiology 211:325-336, 1999

35. Veith FJ, Marin ML: The present status of endoluminal stented grafts for the treatment of aneurysms, traumatic injuries and arterial occlusions. Cardiovasc Surg 4:3-7, 1996

36. Wakhloo AK, Lanzino G, Lieber BB, et al: Stents for intracranial aneurysms: the beginning of a new endovascular era? Neurosurgery 43:377-379, 1998

37. Yamashita K, Okamoto S, Kim C, et al: Emergent treatment of iatrogenic dissection of the internal carotid artery with the Palmaz-Schatz stent - case report. Neurol Med Chir 37:336-339, 1997

Manuscript received September 15, 2004

Accepted in final form October 11, 2004

Address reprint requests to: Pascal Jabbour, M.D., 909 Walnut Street, 3rd Floor, Philadelphia, Pennsylvania 19107. email: Pascal.jabbour@mail.tju.edu. 